\title{
Toward the Reformulation of International Refugee Law Symposium Report
}

\author{
Bill Frelick
}

On May 18-21, 1995, forty international lawyers, social scientists, government officials, and representatives of intergovernmental and nongovernmental organizations gathered in Toronto to participate in a collaborative exercise, termed the Reformulation Project, to analyze and critique a proposed reformulation of the international refugee regime. General Rapporteur, Bill Frelick, presents this synthesis of the Meeting's workshop and plenary discussions.

\section{The Reformulation Project Idea}

The post-Cold War refugee reality is increasingly characterized by the notion of non-entrée, the containment of refugee flows either in the country of origin or in the region of origin. Keeping refugees out of potential receiving countries, through various visa and border controls, prevents refugees from availing themselves of the protection of international and domestic refugee law that entry would bring.

Since World War II, most Northern states have built a link between refugee protection and immigration. Persons recognized as refugees, usually, have been allowed to remain in host states on a permanent basis. However, even those societies most open to immigration, for example, the United States and Canada, have signalled their unwillingness to continue high levels of immigration generally, and their specific unwillingness, to be open to the arrival of asylum-seekers. Because the link between refugee protection and immigrant benefits has been axiomatic, the effect has been for gov-

Bill Frelick, General Rapporteur to the Reformulation Conference, is a Senior Policy Analyst with the U.S. Committee for Refugees, Washington, D.C. ernments to erect barriers to prevent asylum-seekers from entering for fear that the governments would then be obliged to adjudicate the asylum-seekers' refugee claims and provide permanent immigration benefits to those qualifying as refugees.

Related to the increased incidence of non-entrée are two factors under the current refugee regime that create inequities in the treatment of refugees. First, protection is being proffered to a smaller and smaller percentage of the world's refugees who have the good fortune, means, or talent to surmount the obstacles to entry, gain a foothold in a receiving state, and avail themselves of that state's protection. Who benefits from protection is less related raphy, find refugees crossing their borders, and are left to carry a burden not of their own making with inadequate support from the rest of the international community.

The problem confronted by the Reformulation Project, therefore, is to provide a twofold basis for enhanced international coordination to protect refugees: first, by guaranteeing them unhindered access, the right to flee their countries and to seek asylum in other countries based on a broader refugee definition; and second, to share burdens and responsibilities among states more equitably.

The central feature underlying the Reformulation Project is the notion that, as a rule, refugee protection ought to a comparative index of risk of persecution than to the ability of the claimant to enter and to negotiate complex asylum adjudication systems. The tendency of governments has been not only to restrict access to asylum-seekers physically and legally, but also to interpret the refugee definition ever more narrowly so that the number of asylum-seekers who succeed in entering and who are recognized as refugees appears to be a shrinking proportion of the total number of refugees and would-be refugees in need of protection worldwide. This narrowing of the refugee definition, as it is interpreted by states, ironically comes at a time in history when a broader definition is called for. The second consequence of the current regime is that a disproportionate burden is visited on countries or regions of first asylum, who, due to the happenstance of geog- to be temporary, and that permanent protection ought to be considered as the exception, the solution for residual cases for whom, after a period of time, repatriation in safety and dignity is not possible. The Project also insists that a more equitable and binding system of international burden sharing, both human and fiscal, is necessary to enable states of first asylum to keep their doors open. Finally, the Project calls for greater emphasis on laying the groundwork for eventual repatriation through training and development.

\section{Temporary Protection}

The centerpiece of the Reformulation Project enterprise is the idea that refugee protection ought to be conceived of as a temporary palliative to provide a broad level of protection to refugees for a limited period of time. A balancing act is called for between, on the one 
hand, ensuring that temporary protection is humane, and, on the other, not encouraging the development of roots that will compromise the goal of eventual repatriation to the country of origin.

The workshop discussion, as well as the Study in Action, seemed focused more on the criteria for the humaneness of temporary protection than on the implications this might have on encouraging voluntary repatriation at a later point in time. The willingness of states to embrace the Reformulation Project, however, is predicated on the idea that temporary protection will be the norm. Since, heretofore, permanent protection has been the norm (even for groups who supposedly were being offered only temporary asylum), governments will need to be convinced (against the body of available empirical evidence) that protection can be viable on a temporary basis, and that temporary protection will not simply mean delayed immigration; a "slow way of saying 'yes' to permanent admission," as one observer put it.

The two critical issues in this regard seem to be (1) the duration of temporary protection and (2) freedom of movement for persons enjoying temporary protection-the time/space continuum, so to speak.

Both the workshop and the Study in Action were committed to guaranteeing refugees in temporary protection the full panoply of rights enshrined in international human rights instruments. The commitment to upholding basic human rights standards was viewed as unconditional, regardless of the possible effect on the willingness of refugees to repatriate. Nevertheless, it was recognized that some governments, particularly in the South, would be reluctant to move away from restricting the movement of refugees, as this relates to security concerns, the protection of local markets, deterring local integration and paving the way for repatriation as the preferred durable solution. In the North, as well, it was pointed out that integration produces non-return; Salvadoreans in the United States were cited as an example of a group provided temporary protected status who would not voluntarily return after peace was restored in the home country. The tension between states' interests in restricting refugee movement and the consequences of such restrictions in terms of human rights and psychosocial needs was not fully explored or resolved.

The Study in Action proposed a maximum temporary protection duration of not more than five years. For those persons who are not able to return after five years, permanent residence would be offered in the country of temporary protection or in a third state. This also involves a balancing between the time generally required for conflict resolution and the desire to limit the extent to which refugees are

nent residence solution would take place somewhere other than the country of temporary asylum)? There was also some concern that a fixed date could precipitate refoulement; as the five-year deadline approached, states might be more inclined to decide (or press an international supervisory agency to decide) that conditions were sufficiently improved for refugees to return, even if that was not the case.

The five-year duration of temporary protection might be a hard sell in Africa, where, in effect, temporary protection is the indefinite condition of most refugee populations. The tradeoff is and has been one of international financial assistance to host countries in return for their support for refugees. If refugees who cannot return are

\section{Who benefits from protection is less related to a comparative index of risk of persecution than to the ability of the claimant to enter and to negotiate complex asylum adjudication systems.}

in legal limbo. Allowing for exceptions for vulnerable groups who could be offered permanent residence sooner, five years was considered the appropriate balance that would be long enough to allow situations in the home country to be resolved and short enough to account for the psychosocial needs of the refugees.

Several questions remained. What is the utility in setting one, universal standard of five years as the maximum duration for temporary protection? Is more flexibility needed on a case-bycase basis, so that, for example, when refugees and host populations are culturally similar and a high level of political solidarity exists, (such as when Iran and Pakistan hosted Afghan refugees in the 1980s) ten years would be a duration that would not do any harm to the psychosocial needs of the refugees? However, would the obverse hold? If a host country was hostile and politically and/or culturally incompatible with the refugee population would that mean that a period of less than 5 years could be set as the maximum duration? Would this give states an incentive to be less hospitable to refugees (assuming that the perma- deemed to be permanent residents after five years, and if international refugee assistance funding stops at that time, then the African states that host long-term refugee populations stand to lose significant revenues through the suggested reformulated system.

Although the workshop discussed some studies analysing durations of refugee stays in the 1970s, it did not have enough empirical evidence about the numbers and types of refugees who might not be able to return after five years to draw conclusions about who and how many might require durable solutions other than repatriation.

Termination of temporary protection was not discussed in great detail in either the workshop or plenary session. The Study in Action did address measures that could be taken to avoid the necessity of mandated repatriation, which would be considered the option of last resort. Little attention was paid, however, to the standards for the termination of refugee status for former refugees or for rejected asylumseekers, and for the methods and standards governing removal for those unwilling to repatriate voluntarily. 
A major concern expressed in the workshop, with implications for the viability of the Reformulation Project itself, is whether there could, in fact, be a quid pro quo, whereby the willingness of states to adopt temporary protection (and other features of the Reformulation Project) would, in fact, be linked to the dismantling of non-entrée barriers. The workshop reached a consensus that the adoption of temporary protection as a norm would not, in itself, induce states to lowernon-entrée bartiers. The response of European states to refugees from former Yugoslavia shows that the creation of a temporary protection regime does not, in itself, result in open borders. In fact, subsequent to the creation of a temporary protection mechanism, visa restrictions were imposed on Bosnians by

tus determination, closed refugee camps, and non-entrée barriers?

\section{Repatriation and Development Assistance}

If the norm of protection is to be temporary, then strong emphasis needs to be placed on repatriation, and how it might be promoted and facilitated. The Study in Action provided a useful, though limited, model for establishing a system of development that would foster repatriation. Its "bottom-up" model placed emphasis on the creation of grassroots refugee development councils and local development councils to coordinate sustainable development plans for returnees and "stayees" - the local populations that did not become refugees. This model, though promising in itself, seemed

\section{The central feature underlying the Reformulation Project is the notion that, as a rule, refugee protection ought to be temporary, and that permanent protection ought to be considered as the exception, the solution for residual cases for whom, after a period of time, repatriation in safety and dignity is not possible}

most European states. However, it was also pointed out, that the temporary protection scheme adopted in Europe in response to the Bosnian crisis did not include a responsibility sharing agreement, creating an incentive to impose access barriers for fear that open countries would receive a disproportionate share of the burden, even if on a temporary basis. This view suggests that the Reformulation Project, if fully implemented, could have the hoped for result in allowing unrestricted access for refugees. However, the unwillingness of European states to enter into a responsibility sharing agreement for Bosnians in temporary protection suggests the difficulty of fully implementing the proposal.

This raises the following question for the proponents of the Reformulation Project: What would be accomplished if states choose certain features of the Project that they find attractivesuch as temporary rather than permanent protection-and yet maintain a strict refugee definition, sovereign sta- weighted in the direction of rural refugees from the South fleeing from civilwar related conflicts. Lacking were models for promoting repatriation among other important components of the refugee reality, such as urban refugees.

The construction of a South-South development/repatriation model, while useful in itself, is not a sufficient building block on which to erect the Reformulation Project edifice. Attention needs to be paid to models for stimulating voluntary repatriation from North to South (which is likely to be the more difficult enterprise), if Northern governments are to be convinced to buy into the reformulated refugee regime. The workshop, while characterizing the Study in Action model as "good," suggested that it might be overly optimistic and-as is often the case with models-somewhat too neat a formulation that might fail to take politics and other human foibles into account. It was pointed out the likelihood of tensions between lo- cal host populations and refugees and within the refugee communities themselves.

Concerns were raised in the workshop that the Study in Action, in keeping within the parameters of the Reformulation Project, did not address the issue of root causes. Ironically, however, the emphasis on development does implicitly suggest an economic "root cause." The suggestion that development is an indispensable component for solving the refugee dilemma implies that the grounding for the displacement is economic. This assumption might need further examination. It would seem to be more consistent with the current-or reformulated-refugee definition to link repatriation with improvements in human rights conditions and to place greater emphasis on conflict resolution, perhaps utilizing similar refugee and local development council models.

The Study in Action briefly touched on the criteria for safe and dignified return. In one instance, it articulated a standard of a "clear and imminent danger to the safety of returnees" as the basis for determining the advisability of repatriation, and suggested identifying "repatriation enclaves" to which refugees who desired to return could go when "pervasive conflict" continues in the country of origin. These ideas, controversial in themselves, were not addressed by the workshop because they were considered to be outside the scope of the workshop's mandate.

\section{Responsibility Sharing}

In order to dismantle non-entrée barriers and to convince states to allow refugees access to temporary asylum on their territories, the Reformulation Project needs to develop a system that will assure states that opening their borders to refugees will not result in overwhelming refugee flows with which they alone will have to cope.

The workshop proposed that states would identify "risk-regions" on a fluid and ad hoc basis as a means of sharing responsibility for hosting refugee populations. The risk-region 
would be supported by a universal system of fiscal burden sharing. The Study in Action argued that a more universalized system for sharing responsibility for hosting refugees was not tenable, citing the ad hoc nature of refugee movements and host state responses, and the interests of states in maintaining regional security. Also cited in support of this thesis was the example of Africa, where the concern of African states seems to be less with sharing responsibility for hosting refugee populations than with receiving adequate financial support to accommodate those populations and to ease the burden on the local host population.

According to the risk-region model, those states that perceive the threat of unmanaged refugee migration would join together in regional groupings to attenuate the impact of such migration by sharing responsibility for hosting refugees among themselves. Partners in a risk-region would be more likely than those outside the region to be motivated to address the resolution of refugee-producing conflicts, as well as longer-term development as a means to encourage repatriation.

There were unresolved questions about how responsibilities for hosting refugees would be allocated among states and concern about refugees being treated as commodities as governments and international agencies negotiated moving them from sites of arrival to sites of temporary protection. How, for example, would countries of first asylum respond if refugees refused to be moved from the site of arrival to other countries of temporary asylum? Assuming strict adherence to the principle of non-refoulement, could refugees be involuntarily transferred among asylum states according to responsibility sharing agreements they might enter into?

A related question is how the allocation of responsibility sharing among states would relate to the dismantling of non-entrée barriers. If the Reformulation Project's system of refugee responsibility sharing is intended to be minimally coercive, and if refugees are free to move, then it could be anticipated that far greater numbers of refugees (largely from the South) would likely move to more attractive states of asylum (largely in the North), particularly in the absence of barriers to their onward movement. Would refugee responsibility sharing agreements involve the return/relocation of such refugees to the region of first asylum? If so, does this mean, in effect, that nonentrée barriers would only be objectionable where direct refoulement was imminent, i.e., in countries of first asylum?

The workshop felt that rules for refugee responsibility sharing would have to be ad hoc, and that it would be unrealistic to think that responsibility levels could be set and stipulated through a treaty-based obligation. Nevertheless, the workshop did discuss the factors that would be used as principled criteria for determining responsibility sharing obligations, based largely on determinations of each state's absorptive capacity.

There was some concern that the regional approach, in effect, amounted to a "buying out" of refugee responsibility sharing on the part of Northern states; contributing money instead of making their territories available to refugees themselves. While there seemed to be general uneasiness with this prospect, and while it seemed contrary to the original intent of the Reformulation Project, there also appeared to be a grudging consensus that it would be unlikely to expect states to share universally in hosting of refugee populations, and that a "buy out" might be the best concession that could be won from states unwilling to host refugees within their territories.

In response to this concern, one model that might be explored further would be to employ a regional approach for hosting the bulk of refugees during their first five years of temporary protection. However, for the residual population for whom a durable solution is needed after five years, a permanent resettlement off-take to third countries outside the region could be elaborated. This is the ap- proach that has been followed (more or less) for Southeast Asian refugees, and serves as an example of responsibility sharing among state actors within and outside a risk-region.

Elaborating such a model in greater detail would address an issue that the Reformulation Project has tended to downplay: What will be the significance of the "residual" refugee populations who can't go home? How should permanent exile be factored in as a realistic outcome for significant numbers of the world's refugees? Even a system that is based principally on the goal of temporary protection needs to devise a credible solution for those needing permanent protection in exile.

\section{Fiscal Burden Sharing}

This Study in Action and workshop covered much of the same ground as those considering responsibility sharing, in terms of trying to develop a model for fair and equitable distribution of the fiscal burden of caring for refugees so that no state or region would be disproportionately saddled with this obligation. Although the Study in Action and the workshop took a somewhat more abstract approach toward the development of such a model, they appeared to arrive at a similar place as those dealing with responsibility sharing (or, at least the General Rapporteur will seek to identify and synthesize the complementary aspects of the two models).

The distributive model proposed in the Study in Action and modified by the workshop to include the concept of states as stakeholders, puts a greater emphasis on regional responses and responsibility than a purely multilateral/universalist one, but, like the riskregion model, includes a broader concept of region than would be conceived of according to a pure alliance construct.

The Study in Action takes the Reformulation Project in a direction that was not part of the original conception of the project-promoting the idea of preventive humanitarian action. Although the post-Cold War political landscape is littered with examples of 
the failure of preventive humanitarian action, and the misuse of this concept to bolster and rationalize the current international non-entrée regime, the idea of preventive humanitarian action seems nevertheless to be an element that ought to be factored into a system of risk-region management and fiscal burden sharing. A cost-benefit analysis can't help but find preventive humanitarian action to be an appealing idea, given the immense costs of full-blown humanitarian disasters. As conceived by the Study in Action, preventive humanitarian action would also require greater coordination between relief and development, an idea that was also promoted in the Study in Action on Repatriation and Development Assistance.

The Study in Action's emphasis on countries of origin, although rejected in the original Reformulation Project design, seems to be a logical extension of the Responsibility Sharing workshop's idea of a risk-region by including within the region of risk the refugees' country of origin. This model also seems to relate quite favourably to the ideas advanced in the Study in Action and workshop dealing with repatriation and development, on the need to pave the way for repatriation through the creation of sustainable development projects in the country of origin. If international financial burden sharing is going to include the cost of development in the country of origin as part of repatriation schemes, it seems only logical that the allocation of such costs would also factor in preventive measures in countries of origin.

A number of issues remained unresolved relating to fiscal burden sharing. A major selling point of the Reformulation Project has been the anticipated cost savings if states are no longer required to expend enormous funds on elaborate refugee determination procedures and non-entrée mechanisms. Although some states seemed to have successfully transferred savings from these budgets into refugee assistance and development programs, it was clear that for many states a direct trade-off of savings from one departmental "account" to another would not be possible.

How then would funds be raised to make the Reformulation Project system work? The workshop and the plenary session suggested some interesting possibilities. But the focus mighthave been too narrow. Although the workshop's mandate was fiscal burden sharing, this should be conceived broadly to include non-cash resources, such as labour, goods, and land, that would need to be included in any allocation/assessment of state burden sharing contributions.

Also left unresolved was whether contributions ought to be assessed as part of membership requirement in the UN or whether, as is currently the case with UNHCR, the contributions should be voluntary. Although the original concept of the Reformulation Project was that a binding system of assessed contributions was required, several participants questioned whether a binding system would succeed in raising any more funds than the current voluntary pledge/donation system. It seemed that more study was needed on this question to determine which method was likely to result in greater and more consistent support for UNHCR (or some newly conceived international refugee agency).

\section{International Administration}

This workshop decided early on that the form of any international supervisory agency (ISA) should follow its function, and that, since the workshop did not have the benefit of the construction of the other building blocks, they could not yet agree upon an appropriate administrative structure for the enterprise as a whole. Nevertheless, the workshop was able to reach consensus on several key points from which the beginnings of an administrative structure could be discerned. The workshop participants had serious reservations that a universal institution could or should be responsible for the whole status determination process, the allocation of refugees among states for temporary protection, or the return of refugees nolonger in need of protection or rejected asylum-seekers.

The workshop identified the centrality of states in any refugee regime, and concluded that any ISA would be state-driven, since states would not concede what they see as core sovereign state functions, including decisions on status determination and immigration and border controls.

The Reformulation Project assumes a simpler, more inclusive refugee definition that would make for easier and cheaper status determination, especially through group recognition. But what about negative determinations? The workshop concluded that negative determinations would have to be individualized and include due process guarantees that would meet basic fairness criteria. The ISA could monitor and coordinate status determination, but the actual adjudicatory function, the workshop indicated, would remain a state responsibility. Similarly, the workshop felt that the ISA would have to steer clear of any operational role in returning persons not in need of protection, as assuming a police function would undercut its protection mandate.

These conclusions were reached based on considerations both of sovereignty and cost-effectiveness. Although the ISA would not have an operational role in status determination or removals, the workshop suggested that the ISA should have a strong advisory role. It suggested that the ISA's role could include issuing statements on positive group determinations, issuing procedural guidelines, and giving advice on particular cases. The importance of regionalism in restructuring the refugee regime into a workable system was a theme that ran through most workshop discussions, including this one. The workshop participants argued that states would have more ownership over a system administered on a regional basis, resulting in greater efficiency and more generous standards (as in the case of the OAU definition). 
The workshop cautioned, however that the model of regionally based refugee responsibility sharing proposed in the Responsibility Sharing Study in Action could result in regional confinement by coercively maintaining refugees in one region. The workshop maintained that the regionalization of the system had to be linked to the principle of free access. Given other proposals currently under discussion (the "Reception in the Region of Origin" project of the Intergovernmental Consultations on Asylum, Refugee and Migration Policies in Europe, North America and Australia, for example), this concern ought to be looked at more closely.

The issue of sovereignty went to the heart of the Reformulation Project. Some argued that states would never accept an ISA that could tell them who and how many refugees to accept. The Project rests on the idea that states would be willing to make such a compromise if the protection offered were temporary and the costs shared. With such a limited track record to draw on to show the success of temporary protection schemes, however, the onus is on the Project to convince governments through the force of argumentlogic, morality, and political benefit-of its validity and viability

In any event, consensus seemed to gel around the concept of the ISA-in all likelihood, a reformed UNHCRas a coordinating institution whose role would be defined, largely, as maintaining consistent and universal standards of refugee protection and responsibility through a regionalized system of consensual participation among states. Greater cooperation among states toward a regime of enhanced protection could be won if states were convinced that their obligations would be temporary and equitably shared.

\section{Conclusion}

The workshops were not intended to formulate resolutions, nor was the final plenary expected to vote or otherwise arrive at a concluding document or statement. The observations expressed in the final plenary reflected the personal views of those articulating them, making it difficult to draw a sense of consensus from the participants.

Much of the discussion focused on the political context in which the dialogue regarding reformulation of international refugee law is taking place. If anything approaching a dissenting consensus to a major thrust of the Reformulation Project could be said to have emerged among participants in the symposium, it was a sense of the danger of opening the Pandora's Box of the Refugee Convention (and Proto$\mathrm{col}$ ) for fear that in the present political climate a broader refugee definition would fail and that a more restrictive definition could be fashioned. Some suggested that the Convention has more flexibility, as written, than the Reformulation Project would suggest, and that it can be interpreted more lib-

sponse of governments to the Project. Would states be convinced by the logic of the Project? Fundamentally, would they be willing to sacrifice some of their sovereign prerogatives-primarily in the area of status determination and loosening of immigration controls for asylum-seekers-in return for the benefits of a new regime based on temporary protection and burden sharing? How receptive would they be to the International Supervisory Agency if it was able to fulfill the roles conceived on its behalf by the Reformulation Project?

The root of at least some of the ambivalence towards the Reformulation Project seemed to be a political equation suggesting that the more attractive the concept could be made to States (more specifically, the Northern states), the less palatable it might become to refugee rights advocates. Some saw a danger that the Reformu-

There was concern that if temporary protection became the norm, the model for maintaining refugees in temporary protection would gravitate towards one of isolation and restriction, even detention, rather than empowerment and integration.

erally or more restrictively, depending on the political will of those interpreting it. Creating a new instrument, it was suggested, would not in itself establish such political will. It was also argued that the Convention still has relevance and utility as a critical instrument for confronting restrictive actions by States.

Others observed, however, that governments are moving forward in various ways to devise a more restrictive refugee regime that marginalizes most of the world's refugees and widens the gap between North and South in shouldering the refugee burden. According to this view, the Reformulation Project is unlikely to cause damage to refugee rights, and might have the benefit of presenting States with a more coherent response that satisfies their basic concerns.

Regardless of their views about the merits of the Reformulation Project, the participants, generally, seemed to be keeping an eye on the probable re- lation Project would be taken in bits and pieces, rather than as a whole, and that it ran the risk of providing scholarly legitimacy to governments looking for a rationale for not providing permanent asylum, but having no interest in dropping barriers to access, nor in broadening the refugee definition or sharing responsibility for refugees more equitably. There was concern that if temporary protection became the norm, the model for maintaining refugees in temporary protection would gravitate towards one of isolation and restriction, even detention, rather than empowerment and integration. This would be based on empirical evidence that integration produces non-return. On its face, it seems self-evident that an empowered and integrated refugee is less likely to return voluntarily (except in cases where he or she is motivated to do so for ideological or personal reasons) than a refugee who has been segregated from the host society. Could 
states be convinced to "buy" a binding concept setting standards for treatment of refugees in temporary protection that would meet the requirements of refugee rights advocates? Or would that price be too high, in that they might lose out in their ultimate goal of seeing that refugees do not remain permanently? Ultimately, the deciding factor for states in considering whether to embrace the Reformulation Project may well be the extent to which it binds or does not bind them to certain principles and actions.

Ironically, the deciding factor for refugee rights advocates in determining whether or not they will be able to endorse this Project may well also hinge on the question of free choice. However, in their case, this refers not to the choice exercised by a state in the name of sovereignty and national interests, but rather to the free will and integrity of the individual refugee. To what extent can the Reformulation Project be structured to achieve its objectives of temporary protection and repatriation on a voluntary basis? To what extent would the Project have to rely on coercion to achieve its objectives? The prospect of moving refugees to locations that are not their preferred destinations, as part of responsibility sharing agreements, coupled with enforced removals upon the expiration of temporary protection status, could make it less attractive to refugee rights advocates as an alternative to the present, flawed system. The perceived risk would be that this approach strengthens the hands of states to treat refugees and asylum-seekers as they wish, without taking their interests and choices into account.

There are a number of elements of the Reformulation Project that call for more extensive consideration as the Project develops. Among them would be a discussion of the standards and procedures that have yet to be developed for safe and dignified return. What constitutes a dignified return? Does this require an examination of the relative importance of voluntariness on the part of refugees? The Project's proposed new standard for a refugee definition, replacing the well-founded fear of persecution standard with a more easily decided "serious harm" standard based on the "ability of the state to protect", was not discussed in depth in the May symposium. Although there was considerable discussion regarding repatriation for refugees after it is safe to return, as well as discussion regarding prima facie positive group determination, little attention was paid to persons determined not to be refugees. The due process rights of such persons, and the costs associated with appeals and removals of those "screened out", need to be explored in greater detail.

The symposium was organized for the purpose of subjecting the Reformulation Project to careful and critical examination. As a result, comments in the final plenary often focused on participants' reservations and objections. Few, however, questioned its critique of the limitations of the present regime. In moving from critique of the old to construction of a new regime, however, the Reformulation Project is now in the difficult stage of ascertaining whether the proposal will be able to stand as an alternative system, tested against whatever realities it might encounter. As a result of this scrutiny, some elements will be revised. For example, the Reformulation Project is likely to accord more weight to regional structures of burden sharing as being more consistent with practical realities, as opposed to the more abstract and universal idea originally proposed.

As it now shifts to respond to realworld needs, it becomes increasingly evident that the Reformulation Project is not conceived as an ideal regime or a legal laboratory creation. It comes about and is being developed, rather, as a result of and in response to the very real challenges thrust upon international refugee law in the 1990 s due to the failure of the present regime to provide adequate protection. It ought not, therefore, to be held to a standard that requires it to demonstrate a direct benefit to all the world's refugees and asylum-seekers. Rather, its value ought to be judged according to the extent that it suitably addresses the situations and needs of the majority of the world's refugees, who, it is argued, do flee situations that are likely to be resolved within a five-year period, and who, reasonably, could be expected to return if refugee status did not carry a presumption of permanent exile. The Reformulation Project has the flexibility to allow for exceptions for refugees needing permanent solutions other than repatriation. However, in general, through prima facie group determinations and temporary protection, the Reformulation Project is seen as providing a broader (if shallower) level of protection for most of the world's refugees, at the same time as it would limit some of the benefits for that small percentage of the world's refugees who have successfully navigated non-entrée barriers, undergone individualized asylum procedures, and been granted permanent immigration status: "Reducing the Cadillacs for the few, increasing the bicycles for the many."

Even if the Reformulation Project could be adopted precisely as conceived, there will be those who will never stop advocating for a refugee rights regime that would represent anything less than a Cadillac for all asylum-seekers and refugees, and who will fault the Reformulation Project for its willingness to advocate for less than that ideal. So, we return to our starting point-the political dimension. Refugee law is not conceived (or reconceived) in a political vacuum. If, in reality, first asylum is being denied because a substantial proportion of refugees and would-be refugees are being denied access even to temporary protection, and if the purpose of the Reformulation Project is to devise a system that allows persons faced with serious harm in their home countries to universally seek and enjoy protection from such harm, then it deserves the careful and thoughtful consideration of nongovernmental and state actors alike, who, together, will fashion the new refugee regime reality. 